www.jmscr.igmpublication.org

Impact Factor (SJIF): 6.379

Index Copernicus Value: 79.54

ISSN (e)-2347-176x ISSN (p) 2455-0450

crossrefDOI: https://dx.doi.org/10.18535/jmscr/v6i11.51

Journal Of Medical Science And Clinical Research

IGM Publication

An Official Publication of IGM Publication

\title{
A Comparative study between Inj Sclerotherapy and Threading in treatment of ganglion cyst
}

\author{
Authors \\ Dr S.S. Roychowdhury, Dr Kishlaya Atharwa, Dr Arnab Adak
}

\begin{abstract}
Ganglion cysts are smooth, fluctuant, tense cystic and transilluminant swellings commonly found at the dorsal aspect of the wrist, at the scapholunate articulation. It may involve volar aspect of wrist, tendon sheaths and even interphalangeal joints. This study compares the recurrence rates and complications between two methods of treatment widely accepted for ganglion cysts (e.g. Inj. Sclrotherapy vs Threading). This prospective observational study was conducted on patients who presented to the general surgery outpatient department of our institute with ganglion cysts of wrist. A total of 50 patients were included in the study and the study was conducted from January 2016 to June 2017.

Keywords: Ganglion, Inj. Sclerotherapy, Threading, Sodium tetradecyl sulphate.
\end{abstract}

\section{Introduction}

Tumors of the hand are found to be benign $95 \%$ of the time in the course of excluding a cutaneous malignancy. ${ }^{[1]}$ Representing about $60 \%$ of these benign tumors is the ganglion cyst. ${ }^{[2]}$ Ganglions are tense, smooth, fluctuant, cystic transilluminant swellings. They are the commonest variety of soft tissue tumors of hand ${ }^{[3]}$. They are most commonly found on the dorsum of the wrist overlying the scapholunate articulation, but may also involve the volar aspect of the wrist, tendon sheaths, and even interphalangeal joints. These cysts are nonneoplastic, filled with jelly-like material and may present with chronic pain, inflammation, reduced joint mobility, and even paresthesia ${ }^{[2]}$. These cysts do not have a true epithelial lining and are therefore pseudocysts. The main aim of treatment is to reduce the production of the gelatinous substance contained within it, rather than excision of the cyst. Compression of the median nerve can occur when a volar radial ganglion arises within the carpal canal. ${ }^{[4]}$ The ulnar nerve may also be compressed within the tunnel of Guyon when the ganglion presents on the ulnar side of the wrist. ${ }^{[5]}$ Various procedures have been used to treat a ganglion cyst, e.g. aspiration of the cyst, injection of sclerosant into the cyst, threading of the cyst, and finally surgical excision of the cyst ${ }^{[6]}$. Surgery requires meticulous excision of the whole ganglion complex to prevent recurrence. A moderately invasive procedure is cyst puncture. In this treatment procedure, a suture is passed through the skin perpendicularly through the cyst and is left there for 3 weeks, increasing the risk of infection. ${ }^{[2]}$

This study aims to compare the efficacy, recurrence rates, and complications with the Inj Sclerotherapy and Threading used in the treatment of ganglion cysts. 


\section{Material and Methods}

This prospective observational study was conducted on patients who presented to the general surgery outpatient department at our institute with simple ganglion cysts of the wrist between January 2016 and December 2016 (12 months). A total of 50 patients were included in this study.

Inclusion Criteria: All patients with simple ganglion cyst over wrist

\section{Exclusion Criteria}

- Patients with Local skin lesion e.g. eczema, tinea etc.

- Patients with immunocompromised status e.g. (Diabetes mellitus, H.I.V. etc)

- Complex ganglions

The patients were categorised in the following ways.

- Every first patient- Inj sclerotherapy used

- Every second patient - Threading done

Materials: Disposable $16 \mathrm{G}$ needle, Linen thread no. $2-0,0.5 \%$ bupivacaine

There were 25 patients in each category. Ganglion cysts were diagnosed solely based on clinical examination.

\section{Surgical Technique}

\section{Inj. Sclerotherapy}

Inj sclerotherapy was performed using single dart method (a modification of double dart method). The cyst wall was punctured with a sterile widebore (16-gauge) needle after taking standard aseptic precautions. The gelatinous content of the cyst was aspirated assisted by gentle compression of the ganglion. After the cyst was emptied, the syringe was detached from the needle while keeping the needle in situ. Then another syringe filled with the sclerosant solution was attached to the needle and the cyst was refilled with sclerosant to achieve a size more or less equal to the presclerotherapy size. The needle was removed and the puncture site was sealed with a sterile swab. The patients were advised to use pressure bandage at the wrist for 15 days after each injection for splintage.

\section{Threading}

A clear jelly like fluid aspiration was considered to be confirmatory. Following this, area surrounding the lesion was infiltrated with $0.5 \%$ bupivacaine. A sterile polyamide suture thread no (2-0) was passed through the cyst and taken out from the opposite side. The thread shows a glistening appearance on coming out because of the mucin content thus confirming its passage through the cyst. Another thread was passed at right angle to the former thread in the same way. Continued firm pressure and gentle massage at the centre of the ganglion, resulted expulsion of the mucinous contents of the ganglion out on tothe skin surface with the complete disappearance of swelling. Over a sterile gauze piece the threads were then tied over the cyst firm enough to hold it in place. Care was taken to avoid puckering of the skin. Sterile compression dressing was given. No restriction of activity was advised. On 4th day, the thread was removed at the time of the 1st dressing.

Follow up: In each group the patients were advised follow-up at 10 days, 3months, 6 months and end of the 1st year. The size of the swelling along with any other complications was assessed during each of these visits.

\section{Results}

A total of 50 patients were included in the study. Patients were divided into two groups each containing 25 patients ( $\mathrm{Gr}$ A - treated with Inj. Sclerotherapy and Gr B - treated with threading).Out of total 50 patients, 33 were females and 17 were males showing female preponderance. Dorsal ganglia were commoner than volar ganglia (72.0\%). All the patients had post procedure wrist pain which resolved with analgesics. Maximum follow up period was 12 months (range 6- 12 months) for each group.

In Gr. A 3 patients developed localised rash which resolved with time. At thesite of injection there was superficial infection at 10 days follow up in 1 case. Recurrence was only complication seen in 4 patients within 6 months following the procedure. 


\section{JMSCR Vol||06||Issue||11||Page 287-292||November}

In Gr. B 2 Patients developed mild localised rash which resolved with time. At the entry points of threads there was superficial infection at 10 days follow up in 2 cases which was treated with antibiotics and the final outcome was good.
Recurrence was the only complication seen in 2 patients within 6 months following the procedure. Recurrence in Gr. A over 12 months was found to be in 4 patients (16\%) whereas it was in 2 patients $(8 \%)$ in case of Gr. B.

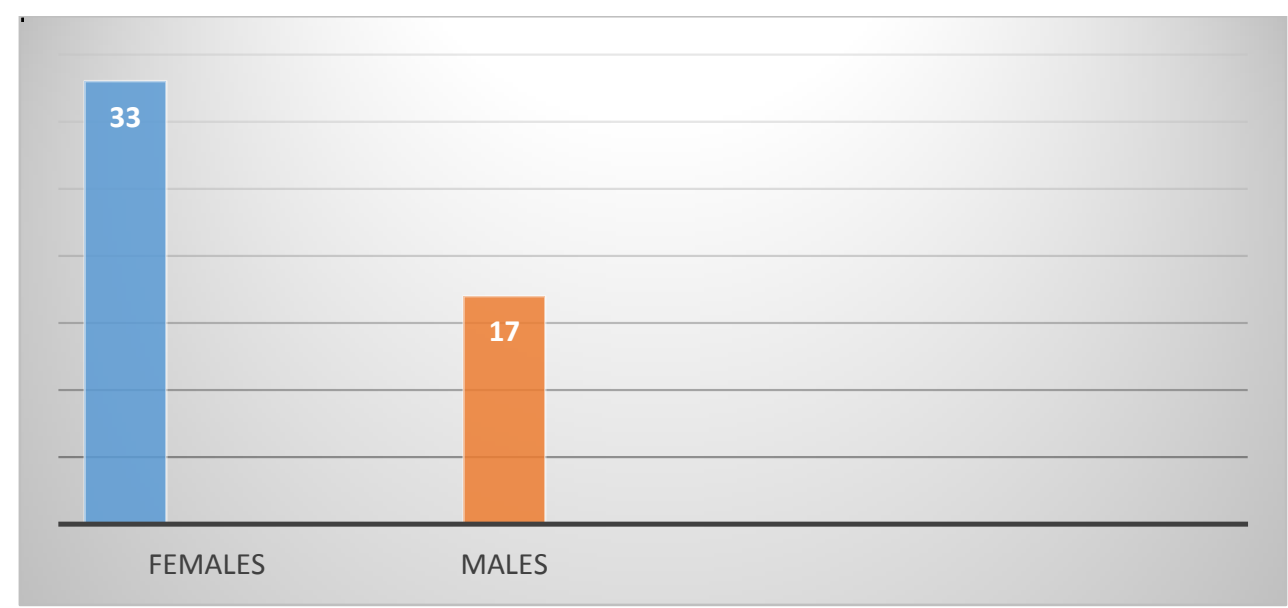

Diag 1 Sexual distribution

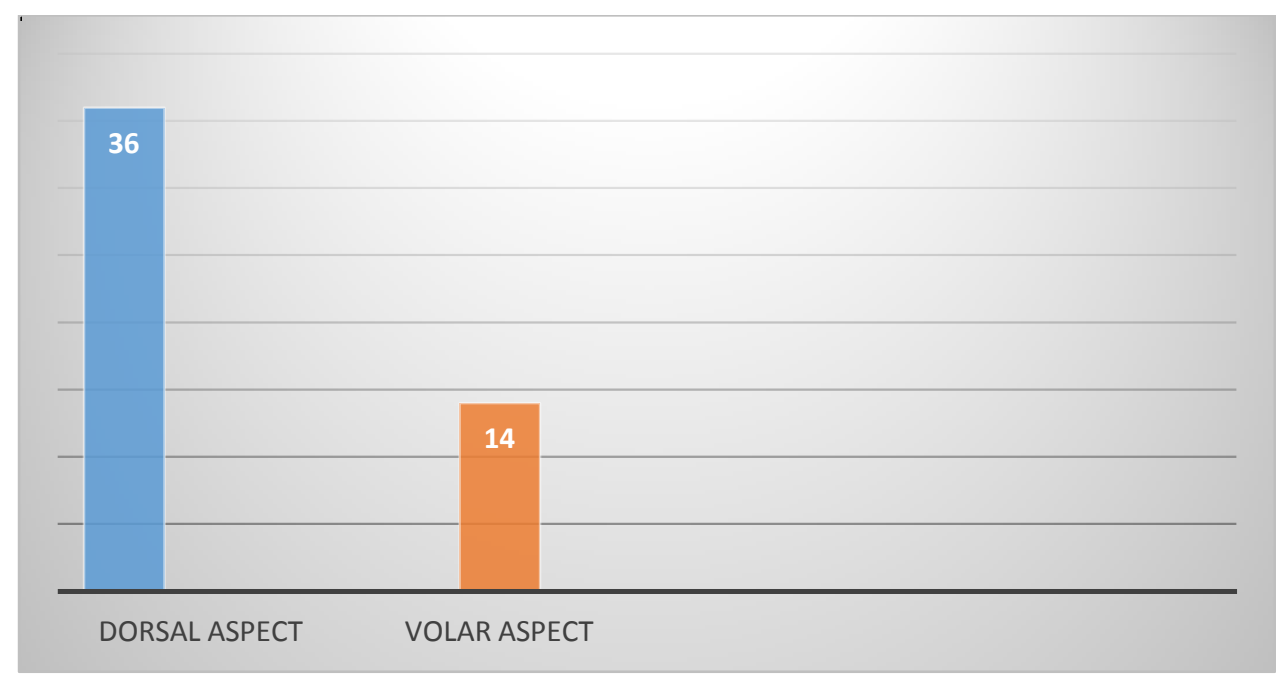

Diag 2 Side of presentation

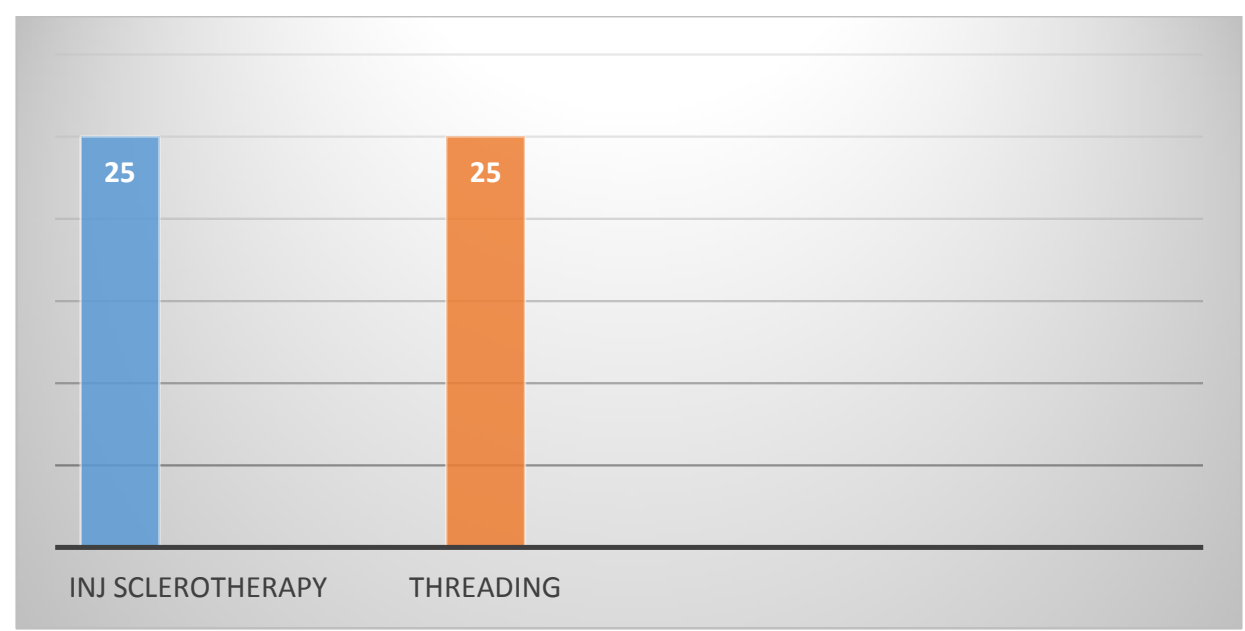

Diag. 3 Patients allotted in each group 


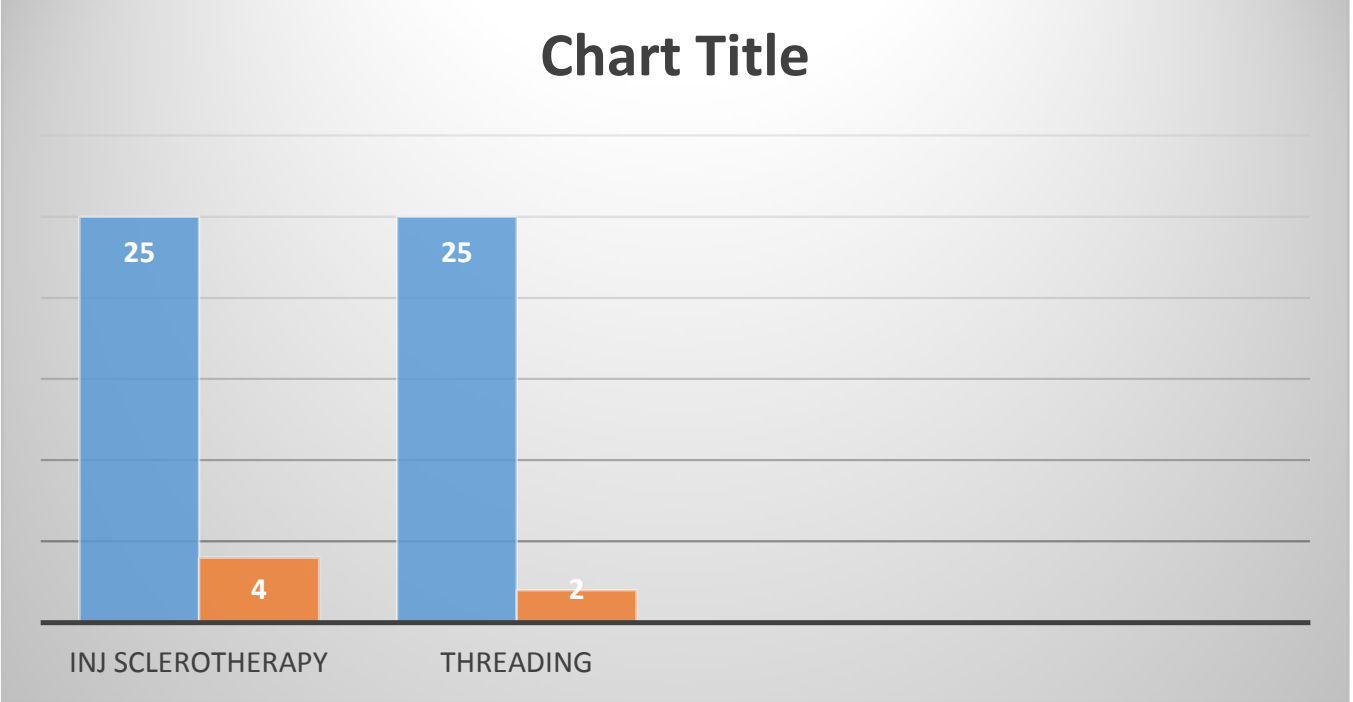

Diag. 4 Showing no. of patients allotted to each group with no. of patients with recurrence in respective groups

\section{Discussion}

Tumors of the hand are found to be benign $95 \%$ of the time in the course of excluding a cutaneous malignancy. ${ }^{[1]}$ Representing about $60 \%$ of these benign tumors is the ganglion cyst. ${ }^{[2]}$ Ganglions are tense, smooth, fluctuant, cystic transilluminant swellings. They are the commonest variety of soft tissue tumors of hand ${ }^{[3]}$. They are most commonly found on the dorsum of the wrist overlying the scapholunate articulation, but may also involve the volar aspect of the wrist, tendon sheaths, and even interphalangeal joints. These cysts are nonneoplastic, filled with jelly-like material and may present with chronic pain, inflammation, reduced joint mobility, and even paresthesia ${ }^{[2]}$. These cysts do not have a true epithelial lining and are therefore pseudocysts. The main aim of treatment is to reduce the production of the gelatinous substance contained within it, rather than excision of the cyst. There are many treatment modalities available for treating it, which in itself indicates that no single effective treatment modality is available without complications. So regarding the treatment of ganglion, a large number of methods have been reported in the literature, bursting of the ganglion manually thumping with a heavy book (traditionally "the Bible") being the most ancient one. ${ }^{[3]}$ It was noted that ganglia taking no treatment occasionally give history of spontaneous disappearance. ${ }^{[7]}$ The methods in use include simply reassurance to the patient, simple aspiration, aspirations and injection of corticosteroid with or without hyaluronidase ${ }^{[3]}$ injection of sclerosing agent ${ }^{[8]}$, manual rupture, cyst wall puncture with a needle, trans-fixation with silk suture ${ }^{[9,10]}$, radical surgical excision, ${ }^{[3]}$ arthroscopic excision ${ }^{[11]}$ and $x$-ray therapy. ${ }^{[12]}$

Cure rates varying from 84-94\% with a recurrence rate of $4-11 \%$ were reported by surgical excision of ganglia. ${ }^{[3,13,14]}$ The low recurrence rate observed by them was because of proper procedure of excision as they have followed and removed the ganglion from the base. ${ }^{[14]}$ The analysis of 62 operative cases revealed the pedicles of ganglia arising from the scapholunate ligament in forty seven (76\%) patients while no definite attachment to the capsule could be found in 2 patients. The pedicles directly entered the capsule in the remainder and were not found to attach to deeper structure. Complications of surgical management of ganglion include risk of keloid formation, nerve injury, post-operative stiffness, instability of scapho-lunate joint and recurrence. ${ }^{[7]}$

Patients who were treated with aspiration and injection of various medications showed cure rates of $57-64 \%$ while those treated with surgical 
excision showed good cure rates of $84-94 \% .^{[3,15]}$ Injection therapy reported the advantages in the form of relatively low recurrence rate (18\%), no scar, simple out-patient treatment which can readily be given by junior doctor, no risk to tendons or neighboring structures, joints, no worsening of the appearance even if injection fails to cure. ${ }^{[15]}$

Looking at all the controversies as evident from previous discussion we tried to search for a safer and equally reliable treatment for the ganglion cyst which should be less invasive and can be performed as a day care treatment. So, we compared two less invasive techniques eg. Inj sclerotherapy and Threading.

Sclerotherapy in treatment of ganglion has commonly been done before using the double-dart technique ${ }^{[6]}$. In the single-dart method used in our study, the needle was not removed from the cyst cavity following aspiration. The injection of the sclerosant was therefore always ensured to be within the cyst cavity. This reduced the rate of complications, such as hypopigmentation, which were due to subcutaneous extravasation of the sclerosant.

Sodium tetradecylsulfate causes obliteration of the cyst cavity, preventing further accumulation of fluid inside the cyst $^{[17]}$. It is reported to have a recurrence rate of $35 \%^{[18]}$.

In our study we used sodium tetradecyl sulphate as sclerosant by single dart technique and out of total 25 patients treated, we achieved a cure rate of $84 \%$ (21 cases) and recurrence rate of $16 \%$ (4 cases).

Gang and Makhlouf ${ }^{[16]}$ introduce the thread technique, by which two sutures were passed through the ganglion at right angles to each other, and each was tied in a loop. The contents of ganglion were expelled by massage at interval. They reported a recurrence rate of $4.8 \%$.In contrast to Gang and Makhlouf ${ }^{[16]}$ who used silk 2/0, we used polyamide suture.

In our study of 25 cases treated by transfixation technique, we achieved a cure rate of $92.0 \%$ (23 cases) and recurrence rate of $8.0 \%$ (only two recurrence), while Kapoor et al. in a similar study, ${ }^{[19]}$ of the 108 cases, 102 cases were followed, cure rate was $96 \%$ with recurrence rate of $4 \%$. In another study carried out by Gang and Makhlouf of the 70 cases treated, ${ }^{[16]} 62$ were followed, $95 \%$ were cured while $5 \%$ had recurrence.

\section{Conclusion}

This study concludes that ganglion cyst in eastern India presents with female sex $(66 \%)$ predilection. The ganglia was seen in $36(72 \%)$ cases on dorsal aspect.

Inj Sclerotherapy and threading both are less invasive techniques available for ganglion cysts with lesser recurrence rates and can be performed as day care basis with local anaesthesia and are very cost effective. In both the techniques there are very few side effects. By comparing recurrence rates of the two methods, threading is found to have lesser recurrence rate $(8 \%)$. Thus threading can be used as a method of treatment of ganglion cyst.

\section{References}

1. Lin SJ, Dumanian GA. Benign hand tumors. Medscape Drugs \& Diseases. Available at http://emedicine.medscape.com/article/128 6448-overview. May 17, 2017; Accessed: October 23, 2017.

2. Thornburg LE. Ganglions of the hand and wrist. J Am AcadOrthop Surg. 1999 JulAug. 7(4):231-8. [Medline].

3. Nelson CL, Saw Miller S, Phalen GS. Ganglion of the wrist and hand. J Bone Joint Surg [Am] 1972;54:1459.[PubMed]

4. Plate AM, Lee SJ, Steiner G, Posner MA. Tumorlike lesions and benign tumors of the hand and wrist. J Am AcadOrthop Surg. 2003 Mar-Apr. 11(2):129-41. [Medline].

5. Kwak KW, Kim MS, Chang CH, Kim SH. Ulnar Nerve Compression in Guyon's Canal by Ganglion Cyst. $J$ Korean 
Neurosurg Soc. 2011 Feb. 49(2):139-41. [Medline]. [Full Text].

6. Dharamdas P, Nayak D, Mathur RK, Kushwah K. Double dart technique of installation of triamcinolone in ganglion over the wrist. J CutanAesthet Surg. 2010;3(1):29-31. doi: 10.4103/09742077.63286. [PMC free article] [PubMed] [Cross Ref]

7. Clay NR, Clement DA. The treatment of wrist ganglia by radical excision. J Hand Surg 1988; 13-B: 187-191.

8. Paul AS, Sochart DH. Improving the results of ganglion aspiration by the use of hyaluronidase.J Hand Surg 1997; 22-B: 219-221.

9. Shapiro PS, Seitz WH. Non neoplastic tumours of the hand and upper extremity. Hand Clinics 1995; 11: 133-60.

10. Angelides AC. Ganglios of the hand and wrist. In: Green DP, Operative hand surgery. 2nd Ed. New York: Chirchill Livingstone, 1998: 2281-99.

11. Sanders WE. The occult dorsal carpal ganglion. J Hand Surg (Br) 1985; 10: 25760.

12. Noppachrt L, Vajara W. Randomized controlled trial between surgery and aspiration combined with methylprednisolon acetate injection plus wrist immobilization in the treatment of dorsal carpal ganglion. J M Assoc Thai, 2004; 87 (12): 1513.

13. De Orsay RH, Mecray PM, Ferguson LK. Pathology and treatment of ganglion. Am J Surg 1937;36: 313-9

14. Barnes WE, Larsen RD, Posch JL. Review of ganglia of the hand and wrist with analysis of surgical treatment. Plastic ReconstrSurg 1964; 34: 570-578.
15. McEvedy BV. The simple ganglion: a review of the modes of treatment and an explanation of the frequent failures of surgery. Lancet 1954; 266: 135-136.

16. Gang RK, Makhlouf S. Treatment of ganglia by a thread technique. J Hand Surg 1988; 13-B: 184-186.

17. Neidoff M, Davis TRC, Clay NR. Conservative management of wrist ganglia: aspiration versus steroid infiltration. J Hand Surg. 1997;22:636637. doi: 10.1016/S0266-7681(97)803634.[PubMed] [Cross Ref]

18. Ashindoitiang JA (2012) Preliminary report of the effectiveness of tetracycline sclerotherapy in treatment of ganglion. PlastSurgInt 2012, Article ID 624209, doi:10.1155/2012/624209 [PMC free article] [PubMed]

19. Kapoor H, Arora J, Jain P, Sharma AK, Sharma VK. Trans-fixation of ganglion. Indian J Orthop 2004; 264-6. 